\title{
The Possibility of Changing Meaning in Light of Space and Place
}

\author{
Christine Jonas-Simpson, RN; $\mathrm{PhD}$ \\ Director of Nursing Research, \\ Sunnybrook and Women's College Health Sciences Centre, Toronto, Canada
}

\begin{abstract}
The author considers the possibility of changing meaning in light of space and place. Many questions are raised, including a fundamental question: If we simply choose the meaning of space and place based on personal knowing, regardless of the space and place we are in, does space and place really matter with regard to the possibility of changing meaning? Many possibilities of changing meaning in light of space and place are explored, including the influence of personal knowing, new life experiences and understandings, changes to space and place, unique languaging in space and place, imaging space and place, and engaging in the wonder and mystery of space and place beyond this realm. The possibility of changing meaning is significant in that new meanings open doors to different choices-and living choices is living health.
\end{abstract}

W hile reflecting upon the focus of this column-that is, the possibility of changing meaning in light of space and place - as I ran through a forest in the heart of Toronto, I heard a noise. In that moment, I thought that this very sound, just a week prior, had alarmed me when I was hiking and canoeing with my family through the Rockie Mountains in Alberta, Canada. And yet, this day no fear was experienced when I heard a noise from the woods in Toronto, because I thought the sound might be made by a small animal. When I was in the Rockies (the heart of grizzly country), a very different space and place, with my husband and our two boys, aged 5 and 7, I was highly alert to all the sounds emerging from the forests that fringed the mountainsides. On one hike I recall hearing a noise and turning with a racing heart to see, with much relief, a deer. The meaning we choose in space and place influences our choices. In Alberta we used bear prevention tactics such as shouting out or clapping our hands to prevent an encounter with a bear. Should I have chosen to shout and clap my hands loudly while running through the woods in Toronto, it would have been considered odd. The point is that space and place and the knowledge of that space and place can change meaning. But is it not simply the meaning we choose to give the situation based on personal knowing-that is, knowledge filtered through our own lens-that cocreates our experiences, regardless of the space and place where we find ourselves? The answer seems straightforward, but is it?

We know that two people can choose different meanings about the same space and place. For instance, my now 6-yearold son has no fear of noises in any forest. He could not understand my fear, as we sat along the glacier mountain shore dis- cussing how his wish to travel on his own to the lake was dangerous. Since he did not see any bears while we were hiking through the woods or along the shoreline as we canoed into our camp, the meanings of the noises for him were filled only with wonder and mystery. So, once again, if two human beings cocreate different meanings about the same space and place, then does space and place matter with regard to the possibility of changing meaning? Are space and place simply irrelevant if all meanings are cocreated by humans? Does the personal knowledge of a space and place (such as, the possibility that grizzly bears live in the mountain regions of the North American west and not in Toronto) contribute to the possibility of changing meaning? Of course, but notice that my son and I both had the same knowledge regarding the presence of bears in the area; however, he assigned different meaning to this knowledge than I did, thus his personal knowing was different from mine. Do human beings cocreate similar meanings and experiences in certain spaces and places, such as that of being in a warm, sunny room versus a cold musty dark cellar, or being in a clean, graffiti-free subway system rather than a dirty, graffiti-stained subway system? Can persons cocreate different meanings in regard to the same space and place at different times in their lives? If so, do we actually cocreate our space and place or, do we cocreate our experiences of a space and place that objectively exists?

\section{Space, Place, Cocreation, and Meaning}

To further explicate the possibility of changing meaning in light of space and place, the concepts of space, place,

Key words: human becoming theory, meaning, Parse, place, space 
cocreation, and meaning require definition, for which I turn to the Oxford English Reference Dictionary (1995) and the human becoming theory (Parse, 1998). Space and place are two different concepts and yet they are related. Space is defined in several ways in the Oxford English Reference Dictionary (1995). The two definitions that are used in this column are as follows: "a continuous unlimited area or expanse which may or may not contain objects," and "freedom to think; be oneself" (p. 1387). Place is defined in the following ways: "a particular portion of space, a portion of space occupied by a person or thing ... situations, circumstances . . and a city, town, village ... a residence" (p. 1206). In addition to these definitions, I will also explore the concepts of space and place as cocreations multidimensionally lived as past-presentfuture all-at-once, consistent with the assumptions emerging from the human becoming theory (Parse, 1998). Cocreation is defined by Parse (1998) as "coconstitution" (p. 97), and coconstitution is defined as "coparticipation in creating meaning in situation" (p. 97). So cocreation, then, is how humans participate with the universe, which includes space and place, in creating meaning in situations. When humans cocreate meaning with the universe they do so in place and space, which is open, continuous, and everchanging.

Meaning, according to Parse (1998), "refers to the linguistic and imagined content of something and the interpretation that one gives to something" (p. 29). Here, it is understood how the sounds in the woods in grizzly country were interpreted as a bear, which becomes an imagined possibility in Alberta, but not in Toronto. And yet it is still an individual interpretation, because this was not the interpretation my son gave to the noises, and he was correct, it was not a grizzly! I learned after our hike that two days prior a grizzly bear had been seen on that trail, which confirms that my imagined content of the situation was a possibility. To me, this highlights the most profound paradox of human life: That is, we live in our own worlds of meaning, which are cocreated uniquely with the universe of experiences of space and place. Only we can know the meaning; and yet, at the same time, we are all connected as humans living a oneness in mutual process with the universe that is indivisible, everchanging, and unpredictable (Parse, 2004). In other words we live the universehuman-process, which is a seamless connected oneness that can be felt in moments of deep love, compassion, and connectedness and at the same time, we experience space, place, and life uniquely, even though at times similarly.

\section{Ultimate and Everyday Meaning and the Possibility of Changing Meaning}

Parse (1998) said that meaning "arises with the humanuniverse process and refers to ultimate meaning or purpose in life and the meaning moments of every day living" (p. 29). This is an important distinction, ultimate meaning or purpose in life and the meaning moments of everyday living. Our ultimate purpose in life can be known and understood in the many meaning moments of everyday living when we listen to what gives us joy and contentment, as well as to that which cocreates fear, doubt, and suffering. Meaning also changes as we live life day-by-day, year-by-year and Parse (1998) spoke about the possibility of changing meaning through living new experiences:

Meaning moments change through the living of new experiences that shift imaged values, shedding a different light and thus changing ultimate meaning. Meaning, then, is not static but ever-changing, and thus portends the unknown, the yet to be truths for the moment. (p. 29)

Meaning moments changed for me dramatically when my son Ethan was born still 4 years ago. What first brought me anguish, pain, and suffering transformed to a pathway where I discovered my ultimate purpose in life. Living this new experience, while at first devastating and one that I was not sure I would live through, has brought even more love into our life as a family. The relationship with our son and brother has transformed us beyond the pain of loss and love to one of love and joy. My ultimate purpose was revealed with this new life experience and now I support other bereaved families through my writings, creative projects, research, education, and volunteer work.

The experience of losing and then finding my son in a new way shifted my imaged values and shed light on my life and the ultimate meaning and purpose of my life, as well as shifted the meaning moments of everyday life. The everyday meaning of space and place also changed. For instance, walking down a diaper aisle in a store cocreated suffering soon after my son's passing, while just weeks prior, the diaper aisle was a joy to walk through as we considered and imaged the day we would require diapers for our newborn. The meaning of the same place and space changed and continues to change. Now that we have a new way of connecting and relating with our son, the diaper aisle, 4 years later, is a space and place that no longer cocreates feelings of devastation and sorrow. Thus, as we live new experiences and gain new understandings, meanings transform. Meanings are fluid and can change at any time as we live the past-present-future all-at-once. This becomes explicit as we make choices in light of those meanings. Meaning is always changing and it is cocreated with multidimensional realms of space and place, and with personal knowing. So I ask again, does place and space matter in light of changing meaning? Or, is it purely the cocreated with our interpretations, perspectives, and values that surfaces meaning? Or, is it all of these things? The co prefix of the word cocreation suggests the importance of all of these things, including space and place. The next section is a reflection on the importance of space and place, and the importance of the $c o$ of cocreation is revealed. 


\section{Changing Space and Place Changes Meanings and Choices}

Choices made in space and place can change when the space and place changes and meanings shift. Many profound examples of this can be found in Gladwell's (2002) provocative book, The Tipping Point. I will focus on one of his examples where he described how New York City's (NYC) crime epidemic tipped in the 1990s, which he attributed to one of the rules of the tipping point, the power of context. The tipping point is "the name given to that one dramatic moment in an epidemic when everything can change all at once" (Gladwell, 2002 , p. 9). The power of context reveals that as humans "we are more than just sensitive to changes in context. We are exquisitely sensitive to them" (Gladwell, 2002, p. 140). Gladwell described the transformation of the NYC subway system from one that was filled with daily crime scenes-up to 20,000 felonies a year by the close of the 1980 s- to one of safety in the 1990s. So what happened? Gladwell convincingly argued how the broken windows theory (Kelling \& Colles, 1996), which he said is one and the same with the power of context, provides the best explanation for this transformation. That is, "if a window is broken and left unrepaired, people walking by will conclude that no one cares and no one is in charge. Soon, more windows will be broken, and the sense of anarchy will spread from the building to the street on which it faces, sending a signal that anything goes" (Gladwell, 2002, p. 141), which ultimately can lead to more serious crime. Using the broken glass theory, the NYC subway was cleaned up, literally. Graffiti were removed from the trains and walls and people were charged for fare-beating and urinating in a public space. A different space and place was created for the NYC subway system, one that was safe and clean and where crime was not invited. Parse (1998) said that, "the human is open, freely choosing meaning in situation bearing responsibility for decisions" (p. 21), and that "meaning surfaces as reality is made concrete through a person's choices" (p. 35). Choices about committing crime shifted when individuals' meanings of the subway system shifted from something that invited crime to something that did not. So, to solve major crime and prevent it, Gladwell (2002) suggested that it doesn't require solving the big problems but rather, it requires attending to the little things that give messages of disorder and invite crime, like graffiti and fare-beating. Gladwell's message is incredibly hopeful. Given that I believe that humans freely choose the meaning of space and place, how is it that the meaning of the subway system for most people in NYC shifted from that of an unsafe crime ridden place when it was dirty to a safe place with less crime when it was cleaned up? Is this a cause and effect relationship, or are there certain characteristics of space and place, like order and disorder, that cocreate similar meanings and hence, similar human choices? At any rate, I believe Gladwell's NYC subway example shows the power of the meanings we give to space and place and the power of the $c o$ in cocreation. This happens in the human-universe mutual process; that is, the human's cocreation of meaning happens with the universe of space and place.

\section{Space and Place, Language, and Health}

Another area to explore is how language is involved in the possibility of changing meaning in light of space and place. The first principle of the human becoming theory (Parse, 1998) describes how we cocreate reality through languaging, which is our way of communicating what we value and image through our speaking-being silent and moving- being still. If we cocreate our reality through our languaging, then the possibility of changing meaning in light of space and place is linked with languaging and the paradoxical rhythm of revealing-concealing. For instance we will reveal to a close friend or a spouse something we may not reveal to a colleague, parent, or child. Or, we may reveal something in certain places that offer some privacy and conceal the same thing in other places that are more public. Similarly, persons in hospitals may reveal more to one healthcare provider than another or perhaps, in one space or place of the hospital different from in another. Thus, languaging changes when we are with different people, but also, when we are in different spaces and places, which links to the possibility of changing meanings, hence, making and living different choices, and living choices is, according to Parse (1998), living health.

Gesler (1999) shed light on the power of language and place in his article titled, "Words in Wards: Language, Health and Place." He stated that there is little literature on this topic and suggested that "specific features of rooms in health facilities such as the color of walls, amount of light and the arrangement of furniture, could affect what is being said and how it is interpreted" (p. 21). Thus, being in a hospital room that is filled with light, warm colors, clean floors, and comfortable surroundings may surface different discussions and different meanings than being in a hospital room that is dirty, dark, and dingy. Caring for persons in their home can also shift the ways that persons language their wishes and desires. I learned this as a community health nurse, when the place and space where I cared for my patients was their own home. What is it about space and place that changes the way we speak and hear? What happens in hospitals or community health settings, then, when the space and place is changed? I know I feel differently in one space and place than another; however, isn't it still my own cocreation with this space and place? So, would it matter if the color of the walls changed? When I woke up in a hospital room recently it was filled with warm colors on the walls, sun pouring through the window, and nurses with warm smiles greeting me. This space and place made all the difference to my cocreated meanings, thus to my health. Was it the same for the other patients on this patient care unit? Again, how did people in a large city change the meaning of the subway system that shifted the system 
from a place of violence to one of safety? Are there universal experiences of cocreating meaning in certain spaces and places?

What about the art and science of Feng Shui? Feng Shui, according to Kingston (1999), author of Creating Sacred Space with Feng Shui, is "the art of balancing and harmonizing the flow of natural energies in our surroundings to create beneficial effects in our lives" (p. 4). While this sounds like a cause and effect relationship, I still believe it is the cocreation between space, place, and person that shifts the meaning of the space and place. For instance, Kingston suggested, "clutter clearing is one of the most powerful, transformative aspects of Feng Shui" (p. 11). I know I feel differently when I clean up clutter from my home and office. I literally experience clearer thinking and feel more light and alive. When I am surrounded in clutter I feel heavy, weighted, and drained of energy. When I shift my space and place by cleaning it up it changes my experience and the meaning of my situation changes, as do my choices. There are books and websites with hundreds of testimonies describing the changes Feng Shui has made in people's lives. The science of Feng Shui is based on energy fields and systems. While I believe all that exists is energy, it is the human experience of the energy and the meanings that humans assign to those experiences that most interests me.

\section{Imaging Space, Place, and Experiences With New Understanding}

Recently when I was in the hospital to undergo surgery I was treated with compassion and given excellent, competent healthcare. The compassion I experienced made all the difference in a space and place where I did not have much control and where I depended on others for assistance. When I could barely manage to move my pillows beneath me to create comfort in the hospital bed I reflected back on my nursing career and the people I have cared for in hospitals and long term care and chronic care settings. All I could think of, while in the space and place of a hospital room, was how incredibly strong persons who require hospitalization for an extended period of time must be! I marveled at the strength of older persons for whom I have cared. I imaged the people in the space and places from my past in the present moment and marveled at their fortitude. Somehow I better understood their tolerance, frustrations, resignation, and appreciation for the little things, like accessibility to a tissue, a scratch on the nose when you cannot move your arms, having a call bell easily accessible, and knowing that someone would address the pain.

After running the Washington DC marathon in October 2005 , I had another experience of changing meaning after imaging a space and place from the day prior in the present moment. I wrote the following about my experience:

The next morning, while reclining in our hotel room reading the paper and sipping coffee, albeit with stiff sore muscles and sore toes, we learned that Rosa Parks was being honored at the rotunda on Capital Hill at the time we ran by it. She was the first black American, and the first American citizen in United States history to lie in state. When [my friend] Lynn read this fact from the newspaper, I imaged the moment we ran by Capital Hill with the majestic white building contrasted against the piercing blue sky. Reflecting back on that moment with this new knowledge deepened the experience. Knowing Rosa Parks was there-a courageous woman who sparked a civil rights revolution - created feelings of being even more blessed as I imaged that past moment in the present in a new way. (Jonas-Simpson, 2005, p. 1)

With this new knowledge of the space and place in which I was situated, I lived the past moments in the present moment and the meaning of my experience during the marathon changed. I wonder then, what possibilities this phenomenon holds for those who gain new experiences and understandings and wish to shift meanings cocreated in spaces and places of the past and possibly, the future.

\section{Changing Meaning in a Space and Place Beyond This Realm}

One of the most profound ways that I have experienced shifts in meaning related to space and place has been my ability to connect with my son Ethan after his passing, in a space and place beyond this realm. I connect with him through meditation or through spontaneous explicit-tacit signs in nature, a space and place where our connecting amid our separateness is most strong. From the moment of his passing I felt his presence as a happy, playful child who is with me always. Connecting with Ethan has been helpful to my entire family including my two sons on earth. This past summer, 4 years after his brother's passing, my oldest son, Jonah, said to me that he feels Ethan is no longer lost to him. He said he knows he is with him now. My younger son on earth, Kyle, says that whenever he is frustrated or angry he just reaches up and gets a hug from his brother Ethan. I recall a well-meaning neighbor telling me about 2 months after my son's passing, "you have to move on at some point-don't you?" I knew he meant well but I felt he was asking me to forget my son, which just was not possible, let alone desirable. Many persons who are grieving find reconnections with those who have died to be dramatically helpful in living with loss. Communications with persons after their passing are described in profoundly moving ways (Botkin \& Hogan, 2005; Guggenheim \& Guggenheim, 1995). Botkin and Hogan (2005) referred to Guggenheim and Guggenheim (1995), who coined the term, after death communications (ADC), after interviewing 2,000 people in the United States and Canada about their spontaneous after death communications and connections to persons significant to them. Botkin (as cited in Botkin \& Hogan, 2005) took this one step further and created a technique-a pathway that brings about after death communicationswhich he termed, induced after death communications (IADC). While this term sounds very clinical and initially dis- 
couraged me from reading the book, I continued and was fascinated with the human experiences described and the stories and communications shared. Botkin (as cited in Botkin \& Hogan, 2005) acknowledged that they facilitated the ADC using his technique, but what happens during the experience is completely out of his hands. Grieving persons in the book described a shift in the meaning and experience of their loss of loved ones when they reconnected with them in a space and place beyond this realm. In reading the descriptions of their experiences, I felt that they did not feel their loved ones were lost to them anymore, just as my oldest son described. The grieving persons were comforted to know that their loved ones still existed at another realm, that they were with them, and that they were okay (Botkin \& Hogan, 2005). The reconnection was what Botkin and Hogan (2005) believed dramatically shifted the experience and meaning of the loss of the person from one of devastation to one of comfort and healing. Botkin and Hogan (2005) also described how revisiting the dead persons in a space and place where they were happy and content shifted the grieving persons' former images of them. The former images may have included suffering moments. In follow-up with his clients, Botkin (as cited in Botkin \& Hogan, 2005) found that people continued to feel the joy and comfort of their reconnection. Their lives had changed and had been enhanced as the meaning of the loss shifted when they reconnected with their loved ones. For grieving persons, this opens doors to feelings of peace, contentment, and offers the opportunity to rekindle relationships with others, create new relationships, and engage in meaningful projects and work, which had been difficult for many prior to their reconnections. This is counterintuitive to the conventional beliefs about grief that have dominated the past century. These beliefs posited that relationships with the deceased must be abandoned in order to enable the surviving person to move on in life with new relationships. It is not in letting go of those who have passed on, but rather, it is in the reconnecting with them that enables many to continue to live on in a new way with comfort, contentment, and peace. The notion of connecting with those who have passed on is captured in new grief theories where meaningful connections and continuing bonds, rather than relinquishing bonds, are supported (Klass, Silverman, \& Nickman, 1996; Neimeyer, 2001). Like a tipping point of sorts, the pain of grief unexpectedly and suddenly tipped for persons when they reconnected with those who had passed. The tipping point however, refers to an epidemic that shifts unexpectedly and suddenly (Gladwell, 2002), not one person's experience. The experience of grieving the loss of someone important, however, has likely reached epidemic standing given the number of devastating earthquakes, hurricanes, tsunamis, famines, wars, and victims of AIDS in our world. What would happen for those who struggle with living with loss if they reconnected with loved ones who have passed on in a space and place beyond this realm where they were seen to be okay? Would the epidemic of lingering, painful, grief and sorrow in our world tip? Would this reconnection change experiences of life, health, and quality of life day-to-day?

\section{The Possibility of Changing Meaning in Light of Space and Place}

In this column I have explored the many possibilities of changing meaning in light of space and place. More questions were raised than answered. It seems, however, the possibility of changing meaning in light of space and place is influenced by personal knowing, new life experiences and understandings, changes in space and place, unique languaging in space and place, imaging the space and place of our past, and engaging in the wonder and mystery of space and place beyond this realm. The possibility of changing meaning in light of space and place also links to health. When meanings change in space and place, different choices are made, and living choices is living health (Parse, 1998). I continue to wonder if, as humans, we cocreate the space and place in which we choose meanings and live experiences or, do we cocreate our meanings and experiences from a given space and place. Perhaps humans, with unique personal knowing, cocreate meaning in a given space and place, with the space and place, which cocreates a new space and place, new meanings, and new experiences. As I contemplated the close of this column in the early hours of the morning my son Kyle called out to me in an urgent way. I went to his bedside immediately. He said with much enthusiasm, "Mom, it is like every time I wake up, I am a new person and every time I wake up, I am in a new world!" I thanked him for telling me this and said that I believed each and every day we become more of the who we wish to be in a world that is moving toward more peace and love. His words helped me consider the mystery and wonder of the possibility of changing meaning in our changing world, in a way that is most hopeful. It is my hope that we continue to wonder and dialogue about the possibility of changing meaning in light of space and place, as this reflection, for me, has been a fascinating journey which I continue to travel, especially in light of the possibility of changing meaning with and beyond this realm.

\section{References}

Botkin, A. L., \& Hogan, R. C. (2005). Induced death communication: A new therapy for healing grief and trauma. Charlottesville, VA: Hampton Roads Publishing.

Gesler, W. M. (1999). Words in wards: Language, health and place. Health \& Place, 5(1), 13-25.

Gladwell, M. (2002). The tipping point. New York: Little, Brown \& Co.

Guggenheim, B., \& Guggenheim, J. (1995). Hello from heaven! New York: Bantam.

Jonas-Simpson, C. (2005). The power of imaging. Illuminations: Newsletter of the International Consortium of Parse, 14(2), 1-2,

Kelling, G. L., \& Colles, C. M. (1996). Fixing broken windows. New York: Touchstone.

Kingston, K. (1999). Clear your clutter with Feng Shui. New York: Broadway Books. 
Klass, D., Silverman, P., \& Nickman, S. (Eds.). (1996). Continuing bonds: New understandings of grief. Washington, DC: American Psychological Association Press.

Neimeyer, R. A. (2001). Meaning reconstruction and the experience of loss. Washington, DC: American Psychological Association Press.

Oxford English reference dictionary. (1995). New York: Oxford University Press.
Parse, R. R. (1998). The human becoming school of thought: A perspective for nurses and other health professionals. Thousand Oaks, CA: Sage.

Parse, R. R. (2004). The many meanings of unitary: A plea for clarity. Nursing Science Quarterly, 17, 293. 